(2) Open Access Full Text Article

\title{
Development of a microparticle-based dry
} powder inhalation formulation of ciprofloxacin hydrochloride applying the quality by design approach

\author{
This article was published in the following Dove Press journal: \\ Drug Design, Development and Therapy \\ 12 October 2016 \\ Number of times this article has been viewed
}

\section{Keyhaneh Karimi \\ Edina Pallagi \\ Piroska Szabó-Révész \\ Ildikó Csóka \\ Rita Ambrus}

Faculty of Pharmacy, Institute of Pharmaceutical Technology and Regulatory Affairs, University of Szeged, Szeged, Hungary
Correspondence: Edina Pallagi Faculty of Pharmacy, Institute of Pharmaceutical Technology and Regulatory Affairs, University of Szeged, Eötvos u 6, H-6720 Szeged, Hungary Tel +36 62545575

Fax +3662545571

Email edina.pallagi@pharm.u-szeged.hu

\begin{abstract}
Pulmonary drug delivery of ciprofloxacin hydrochloride offers effective local antibacterial activity and convenience of easy application. Spray drying is a trustworthy technique for the production of ciprofloxacin hydrochloride microparticles. Quality by design $(\mathrm{QbD})$, an up-to-date regulatory-based quality management method, was used to predict the final quality of the product. According to the QbD-based theoretical preliminary parameter ranking and priority classification, dry powder inhalation formulation tests were successfully performed in practice. When focusing on the critical parameters, the practical development was more effective and was in correlation with our previous findings. Spray drying produced spherical microparticles. The dry powder formulations prepared were examined by particle size analysis, scanning electron microscopy, Fourier-transform infrared spectroscopy, X-ray powder diffraction, differential scanning calorimetry, and in vitro drug release and aerodynamic particle size analyses were also performed. These formulations showed an appropriate particle size ranging between 2 and $4 \mu \mathrm{m}$ and displayed an enhanced aerosol performance with fine particle fraction up to $80 \%$.
\end{abstract}

Keywords: antibiotic, carrier-free formulation, quality by design, aerodynamic evaluation, dry powder for inhalation

\section{Introduction}

Using antibiotics in a pulmonary dosage form dates back to 1948 when Abbot Laboratories developed the aerohaler for inhalation containing penicillin $\mathrm{G}$ in a powder form. ${ }^{1}$ The most common treatment for bacterial respiratory infections includes the oral administration of high doses of single or combined antibiotics, which may be associated with severe side effects because of their high systemic bioavailability. ${ }^{2}$ The ability to deliver the therapeutic agents directly to the site of action may improve the therapeutic efficacy for many specific diseases of the respiratory tract ${ }^{3}$ and has numerous advantages over other routes of administration. Lung is a highly absorptive tissue with a large surface area and a limited proteolytic activity, sufficient capillaries, and rapid absorption rate and can be targeted by non-invasive methods. ${ }^{4,5}$ Therefore, direct delivery of antibiotics to a lung infection site leads to much higher drug concentrations in the pulmonary tissue; thus, it may produce therapeutic effects at smaller doses compared to those required by the oral or parenteral routes, ${ }^{6}$ while it is associated with a reduced systemic antibiotic exposure and a reduced risk of toxicity. ${ }^{7}$ 
Ciprofloxacin is a fluoroquinolone antibiotic, a broadspectrum synthetic agent. Its main mechanism of action is the inhibition of the bacterial enzymes DNA gyrase ${ }^{8}$ (topoisomerase II) and topoisomerase IV, thus preventing bacterial DNA from uncoiling and duplicating, leading to cell death. ${ }^{9}$ It has potent and effective activity against a wide range of Gram-positive bacteria like Staphylococcus and Bacillus species and against most Gram-negative microorganisms like Pseudomonas species, and it is often used in the treatment of inhalation anthrax and other lung infections. ${ }^{10}$ Current routes of fluoroquinolone administration include oral, injection, and ocular deliveries, so its formulation as a dry powder inhaler could offer a new possibility of direct pulmonary delivery. ${ }^{10}$ The dry powder inhalation (DPI) formulation is a dosage form containing micronized drug particles that are small enough to be deposited in the lungs. ${ }^{11}$ For local respiratory drug delivery, a particle size of 2-5 $\mu \mathrm{m}$ is of the highest benefit. ${ }^{12}$ A DPI of ciprofloxacin for the treatment of lung infections would be well tolerated and would also minimize the risk for systemic intolerabilities due to minimal systemic exposure. ${ }^{13}$ Clinical investigations show that inhaled antibiotics can decrease the burden and delay the onset of superinfections caused by Gram-negative bacteria such as Pseudomonas aeruginosa. ${ }^{14}$

Quality by design (QbD) is a regulatory-based, modern quality-management system, focusing on the design phase of the development of new pharmaceutical products. ${ }^{15}$ The concepts behind QbD were introduced in international guidelines developed for the pharmaceutical industry. These include the International Council for Harmonisation of Technical Requirements for Pharmaceuticals for Human Use Q8(R2), Q9, and Q10 guidelines ${ }^{16-18}$ that describe the steps and elements of the QbD concept. Nowadays, the application of this quality-management methodology is strongly recommended by regulatory authorities such as the European Medicines Agency and the US Food and Drug Administration. QbD is a risk-based approach with risk assessment (RA) being its most important element. The RA process is capable of identifying the factors that have the highest influence on the quality of a final drug product; these critical factors can be ranked and a theoretical prediction about their effects/significance is made. Applying this approach can reduce the time required for drug development in practice and it also contributes to a more effective allocation of human and financial resources. ${ }^{19}$ Once new pharmaceutical developments are designed by using the QbD methodology, the investigations in practice can be optimized and their effectivity is increased.
The technological aspects of preparing a DPI may follow two possible ways. On the one hand, the conventional, carrier-based formulation method utilizes macrosize lactose with microparticles of the active agent bound to its surface. On the other hand, the effective and modern way of formulation is a carrier-free technology where a special co-formulation containing the active agent plus additives is applied and a microsized final product with a narrow particle size range $(2-4 \mu \mathrm{m})$ and low density $\left(<1 \mathrm{~g} \cdot \mathrm{cm}^{-3}\right)$ is produced. ${ }^{20}$ The importance of carrier-free systems lies in their improved aerodynamical properties, resulting in a highly concentrated drug deposition in the alveolar regions. ${ }^{21}$ When green technology is applied for drug formulation, chemical products and processes are designed, manufactured, and disposed with reduced environmental pollution risk and a lower burden of hazardous substances. ${ }^{22}$ A spraydrying procedure is frequently applied as the method for particle formulation. ${ }^{23}$ Using ethanol as co-solvent can help to produce micronized systems. However, the presence of excipients is also a crucial factor in terms of modifying the surface and stabilizing particle size. Belotti et al concluded that the highest lung deposition was reached upon applying a maximum of $10 \%$ of ethanol beside the excipients. ${ }^{24}$

So far few inhaled antibiotics have been approved or have entered the late stages of clinical development. ${ }^{25}$ Therefore, the goal of our study was to design a DPI of ciprofloxacin hydrochloride (CIP) in the form of a carrier-free system by applying green technology. The $\mathrm{QbD}$ approach in the design phase helps in focusing on connections and effects among the material characteristics, selected production process, investigation methods, and final product properties. The practical product development was performed after the QbDbased RA and theoretical prediction. Microparticles of CIP containing different excipients in optimal concentrations were prepared. The effects of different excipients on the micrometric and aerosolization properties as well as structural characteristics of the DPI products were investigated.

\section{Materials and methods Materials}

CIP, a fluoroquinolone-type antibiotic was kindly supplied by Teva Pharmaceutical Works Ltd. (Debrecen, Hungary). Polyvinyl alcohol 3-88 (PVA), a water-soluble synthetic polymer was purchased from BASF (Cologne, Germany). The amino acid L-leucine (LEU) was obtained from Hungaropharma Ltd. (Budapest, Hungary). Hydroxypropylbeta-cyclodextrin (CD), a cyclic oligosaccharide was donated by Cyclolab Ltd. (Budapest, Hungary). 


\section{Methods}

\section{QbD methodology in formulation design}

As part of the QbD methodology, knowledge space development and RA were performed. To illustrate the relevant knowledge and information, an Ishikawa diagram was set up. The technical tool used for the RA was LeanQbD ${ }^{\mathbb{R}}$ software (QbDWorks LLC, Fremont, CA, USA). In the first step, the desired product was defined and the elements of the quality target product profile (QTPP) were determined. Next, the critical quality attributes (CQAs) and the critical process parameters (CPPs) of the selected production method were identified. CQAs have critical influence on the quality characteristics of the final product and CPPs critically influence the CQAs and QTPPs. In the following step an interdependence rating was performed among the QTPPs and CQAs, and also among the CQAs and CPPs and was categorized on a three-level scale. The interaction between the elements was described as "high" (H), "medium," (M) or "low" (L). Its dynamism is presented in figures generated by the software. This was followed by the probability rating step where CPPs were estimated and categorized on a 10-point scale. Finally, Pareto charts were generated, presenting the numeric data and the ranking of each CQA and CPP.

\section{Preparation of the microparticulate systems}

As a preliminary investigation, solubility tests of CIP were carried out at $25^{\circ} \mathrm{C}$ either in a buffer solution $(\mathrm{pH}=7.4)$ or in distilled water $(\mathrm{pH}=4.4)$. Solubility was measured by ultraviolet/visible spectroscopy (UV/VIS) spectrophotometry (ATI-UNICAM UV/VIS spectrophotometer, Cambridge, UK). The concentration was determined $24 \mathrm{~h}$ after filtering the saturated system.

The significant solubility of CIP in distilled water allows its use as the solvent for spray-drying feed solution. Using $10 \%$ of ethanol in an aqueous solution is known to decrease the particle size because of its fast evaporation during spray drying. ${ }^{24}$ Therefore, the feed solution was prepared by dissolving 1 gram of CIP plus different excipients at different concentrations in an aqueous solution containing $10 \%$ of ethanol. According to our previous research on the effects of organic solvent and additives on the habit (size and morphology) and aerosolization characteristics of DPI systems, ${ }^{26}$ the optimal excipient concentration is achieved as shown in Table 1.

Spray drying is a one-step process through which it is possible to engineer and produce particles directly from solutions with a controlled technique. Hence, spray drying was considered to be the appropriate technique to produce a dry powder for inhalation. The spray-drying process was carried
Table I Composition of the DPI products containing an optimal concentration of excipients

\begin{tabular}{llllll}
\hline No & CIP $(\mathrm{g})$ & LEU $(\mathrm{g})$ & PVA $(\mathrm{g})$ & $\mathrm{CD}(\mathrm{g})$ & Solvent $(\mathrm{mL})$ \\
\hline $\mathrm{I}$ & $\mathrm{I}$ & - & - & - & 50 \\
2 & $\mathrm{I}$ & - & 0.2 & - & 50 \\
3 & $\mathrm{I}$ & - & - & 0.9 & 50 \\
4 & $\mathrm{I}$ & 0.4 & - & - & 50 \\
5 & $\mathrm{I}$ & 0.4 & 0.2 & 0.9 & 50 \\
\hline
\end{tabular}

Abbreviations: DPI, dry powder inhalation; PVA, polyvinyl alcohol; CIP, ciprofloxacin hydrochloride; LEU, L-leucine; CD, cyclodextrin.

out using a Büchi Mini Dryer B-191 (BÜCHI Labortechnik, Flawil, Switzerland); the parameters were optimized as shown in Table $2 .{ }^{26}$ The amount of dry powder yielded was determined between $65 \%$ and $70 \%$. Generally during the spray-drying procedure nearly $30 \%$ of the sample could be lost. So our produced yield correlated with the normal sample production's habit.

\section{Particle size analysis}

Particle size distributions of the spray-dried powders were determined by laser scattering using Malvern (Malvern Mastersizer Scirocco 2000; Malvern Instruments Ltd., Worcestershire, UK). Air was used as the dispersion medium for the microparticles from the entrance to the sample cell. Approximately $500 \mathrm{mg}$ of product was loaded into the feeder tray. The particle size distribution was characterized by the $\mathrm{D}(0.1), \mathrm{D}(0.5)$, and $\mathrm{D}(0.9)$ values and the specific surface area.

\section{Scanning electron microscopy}

The morphology of CIP microparticles was investigated by scanning electron microscopy (Hitachi S4700; Hitachi Scientific Ltd., Tokyo, Japan) at $10 \mathrm{kV}$. The samples were gold-palladium coated $(90 \mathrm{~s}$ ) with a sputter coater (Bio-Rad SC 502; VG Microtech, Uckfield, UK) using an electric potential of $2.0 \mathrm{kV}$ at $10 \mathrm{~mA}$ for $10 \mathrm{~min}$. The air pressure was $1.3-13.0 \mathrm{mPa}$.

\section{Fourier-transform infrared spectroscopy}

Fourier-transform infrared spectroscopy (FT-IR) spectra were recorded with an FT-IR spectrometer (Thermo Nicolet

Table 2 Büchi Mini Dryer B-19I parameters for spray-drying procedure

\begin{tabular}{lllll}
\hline $\begin{array}{l}\text { Inlet } \\
\text { temperature } \\
\left({ }^{\circ} \mathbf{C}\right)\end{array}$ & $\begin{array}{l}\text { Outlet } \\
\text { temperature } \\
\left({ }^{\circ} \mathbf{C}\right)\end{array}$ & $\begin{array}{l}\text { Feed rate } \\
\left(\mathbf{m L} \cdot \mathbf{m i n}^{-1}\right)\end{array}$ & $\begin{array}{l}\text { Aspiration } \\
\text { air }\left(\mathbf{L} \cdot \mathbf{h}^{-1}\right)\end{array}$ & $\begin{array}{l}\text { Aspiration } \\
\text { rate } \\
\left(\mathbf{L} \cdot \mathbf{m i n}^{-1}\right)\end{array}$ \\
\hline 130 & 75 & 5 & 600 & 0.065 \\
\hline
\end{tabular}


AVATAR 330; LabX Midland, ON, Canada) between 4,000 and $400 \mathrm{~cm}^{-1}$, at an optical resolution of $4 \mathrm{~cm}^{-1}$. The sample was mixed with $150 \mathrm{mg}$ of dry $\mathrm{KBr}$ in an agate mortar and the mixture was pressed to obtain self-supporting disks at 10 tons.

\section{X-ray powder diffraction}

The crystal structure of spray-dried powders including different excipients were characterized using an X-ray powder diffraction (XRPD) BRUKER D8 Advance X-ray diffractometer (Bruker AXS GmbH, Karlsruhe, Germany). The powder samples were loaded in contact with a plane quartz glass sample slide with an etched square and measured with a slit-detector $\mathrm{Cu} \mathrm{Ni}$ radiation source. Settings were as follows: voltage, $40 \mathrm{kV}$; current, $40 \mathrm{~mA}$; time constant, $0.1 \mathrm{~s}$; angular step $0.010^{\circ}$.

\section{Differential scanning calorimetry}

The thermal response of each product was measured using a differential scanning calorimeter (Mettler Toledo TG $821^{\mathrm{e}}$ DSC Mettler Inc., Schwerzenbach, Switzerland). About 3-5 mg of powder was precisely weighed into differential scanning calorimetry (DSC) sample pans which were hermetically sealed and lid pierced. Each sample was on equilibrate for $10 \mathrm{~min}$ at ambient temperature before being heated to $400^{\circ} \mathrm{C}$ at a rate of $5^{\circ} \mathrm{C} \cdot \mathrm{min}^{-1}$. Data analysis was performed using the STAR ${ }^{\mathrm{e}}$ software (Mettler Toledo Mettler Inc., Schwerzenbach, Switzerland).

\section{Aerodynamic particle size analysis}

Aerodynamic particle size distribution was determined using a seven-stage Anderson Cascade Impactor (Copley Scientific Ltd., Nottingham, UK). The flow rate was set to $60 \mathrm{~L} \cdot \mathrm{min}^{-1}$.

During the process, the aerosol moved along seven size stages according to the diameter of the particles and was then washed by methanol/phosphate buffer (60/40 v/v \%) to collect the deposited drug. All samples were investigated by UV/VIS spectrometry at $271 \mathrm{~nm}$.

The fine particle fraction (FPF) was established as the number of particles deposited at stage 2 and lower $(\leq 5 \mu \mathrm{m})$, divided by the total initial amount of the particles filled in the inhaler $(10 \mathrm{mg})$. The mass median aerodynamic diameter (MMAD) was defined based on the graph as the particle size at which the line crossed the 50th percentile, indicating the particle diameter at which $50 \%$ of the aerosol particles by mass are larger and $50 \%$ are smaller. ${ }^{27}$ Drug-emitted dose (ED), defined as the percentage of CIP exiting the DPI, was determined by subtracting the amount of CIP remaining in the DPI from the initial mass of CIP loaded. To determine the drug content, $10 \mathrm{mg}$ of the ciprofloxacin-bearing spray-dried microparticles was dissolved in methanol/phosphate buffer (60/40) and analyzed by UV spectroscopy.

\section{Dissolution test: CIP release from the microparticles at $\mathrm{pH} 7.4$}

To check the difference in drug release between the prepared products, $10 \mathrm{~mL}$ of phosphate buffer $(\mathrm{pH} \mathrm{7.4,} \mathrm{as} \mathrm{the} \mathrm{pH}$ in the lung) was used to suspend an equivalent of $50 \mathrm{mg}$ of CIP content in all products. After 1, 2, 3, 4, and $5 \mathrm{~min}$, sample was taken out, filtered, and the concentration measured by UV spectroscopy at a maximum wavelength of $271 \mathrm{~nm}$.

\section{Results and discussion}

\section{Formulation design by the QbD approach}

The first step was setting up an Ishikawa (fishbone) diagram including all the parameters influencing the desired DPI product containing CIP as the active agent. The parameters were ranked into four groups (Figure 1), namely 1) material characteristics, 2) production method, 3) test methods, and 4) product characteristics. This process served as a preliminary knowledge and information collection, which can help in the designing of the experiments and the selection of the CQAs and CPPs of the drug development procedure.

The next step was the selection of the QTPPs, CQAs, and CPPs for the aimed DPI product. Table 3 lists these with their selected targets and their justification, along with the explanations for the classification of the factors selected in each groups.

Figure 2 shows the elements and results of the QbDbased RA. Figure $2 \mathrm{~A}$ presents the interdependence rating of the QTPPs and CQAs, and of the CQAs and CPPs. Each interaction was ranked as high $(\mathrm{H})$, medium $(\mathrm{M})$, or low $(\mathrm{L})$. The same three-level scale was used for the occurrence rating of the CPPs, which is presented in Figure 2B. These interdependence and occurrence ratings were followed by risk estimation calculations using the RA software, which produced a precise impact score (or severity score) for each critical influencing parameter. The calculated and ranked severity scores for the CQAs and CPPs are presented in Pareto charts (Figure 2C) generated by the software. Pareto charts also give a graphical overview of the hierarchy of CQAs and CPPs based on their calculated numerical difference in their influence on the aimed quality of the product. In this special case the particle size (or the specific surface area) of the API is the CQA to have the highest impact on the 


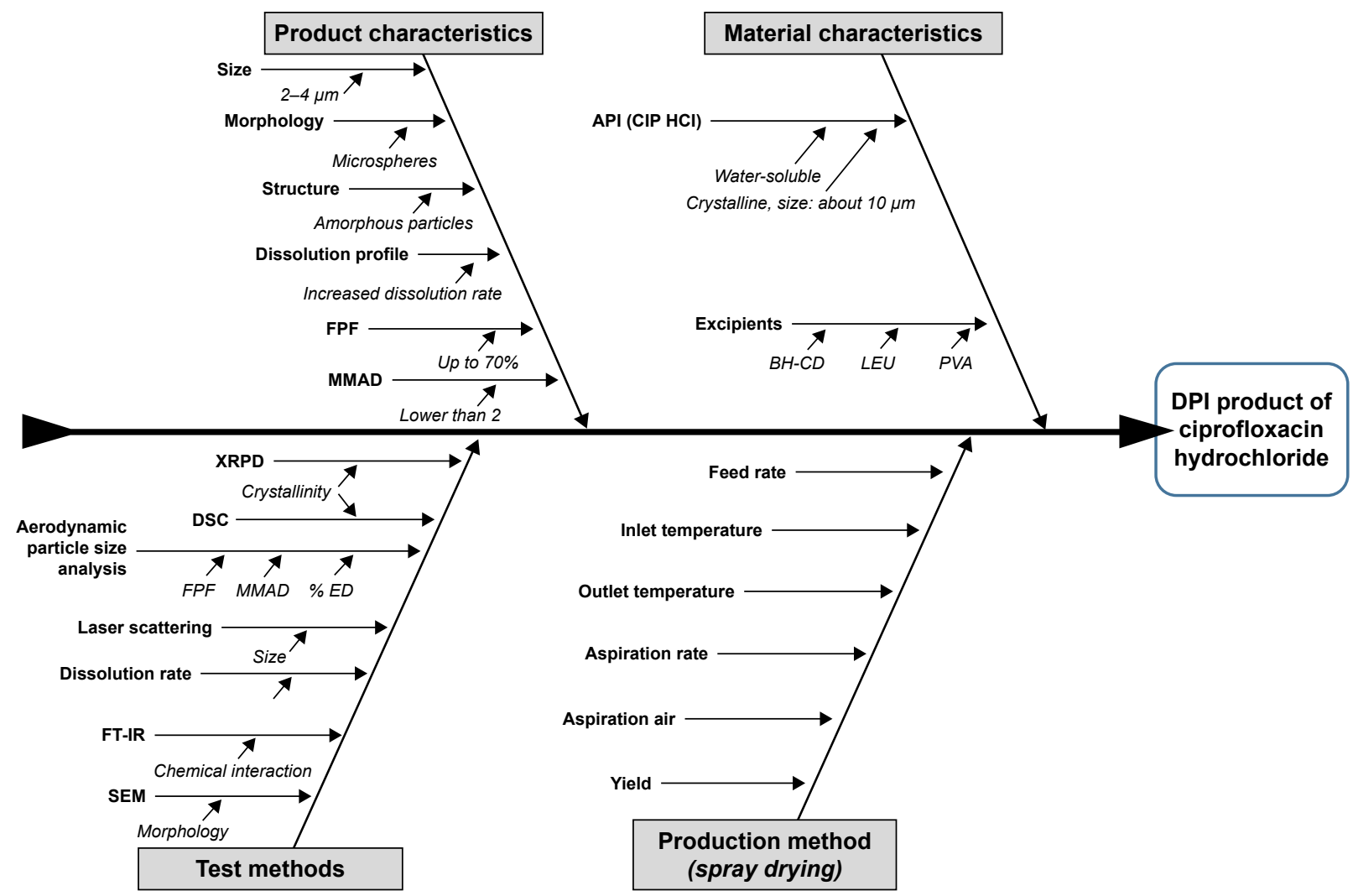

Figure I Ishikawa diagram illustrating the parameters influencing the quality of the ciprofloxacin-containing DPI product.

Abbreviations: DPI, dry powder inhalation; FPF, fine particle fraction; MMAD, mass median aerodynamic diameter; LEU, L-leucine; FT-IR, Fourier-transform infrared spectroscopy; PVA, polyvinyl alcohol.

quality of the aimed final product. It is followed by wettability and dissolution properties. The next ones are appearance and the excipients' profile, while primer solubility and the structure of the API are found to have the lowest impact. The impact of "particle size and SSA" is $41.6 \%$ higher than that of "wettability" and is $47.8 \%$ and $78.9 \%$ higher than the impact of "dissolution" and "appearance", respectively. Comparing "structure" and "particle size", the difference in their impact on the quality of the final product is $183 \%$ for "particle size". Among the CPPs product, "composition" was found to have the highest impact on the desired final product's quality. It is followed by the "outlet temperature", then "inlet temperature", and "feed rate". The impact of the "composition on product quality" is $29 \%$ higher than that of "temperature". Nevertheless, there is a $34 \%$ difference between the critical process factor with the highest effect (composition) and the lowest effect (feed rate) on the final product's properties.

These results of the software-based RA highlight those factors that need the highest attention during the practical development phase when we decide about the exact composition and select the materials and excipients, etc.

\section{Micrometric properties}

\section{Particle size analysis}

Since all the powders were prepared under similar drying conditions, in the spray-drying process the final particle size distributions of the samples were comparable. The smallest particle size was measured for the DPI of CIP containing PVA, while the largest value was measured for the DPI of CIP containing PVA, LEU, and CD as excipients. This size interval is optimal for lung deposition, so a local treatment of the respiratory tract can be achieved by any of the compositions tested.

Microparticulate DPIs had a narrow particle size distribution which is highly advantageous for pulmonary DPI, because it enables the particles to potently target a specific lung region. In consequence, it enables a high deposition of drug particles. Results of the particle size analysis are shown in Table 4.

\section{Particle size morphology}

Field-emission scanning electron micrographs of the spraydried microparticles are shown in Figure 3. The DPI of CIP containing PVA has a relatively smooth surface with 
Table 3 Selected QTPPs, CQAs, and CPPs of a ciprofloxacin-containing DPI formula, their target, justification, and explanation

\begin{tabular}{|c|c|c|}
\hline & Target & Justification/explanation \\
\hline \multicolumn{3}{|l|}{ QTPPs } \\
\hline $\begin{array}{l}\text { Therapeutic } \\
\text { indication }\end{array}$ & $\begin{array}{l}\text { Antibiotic } \\
\text { (respiratory tract } \\
\text { infections) }\end{array}$ & $\begin{array}{l}\text { Antibacterial therapy is essential in respiratory tract infections. Ciprofloxacin is a second- } \\
\text { generation fluoroquinolone antibiotic with a broad spectrum of activity. It is especially effective } \\
\text { against infections caused by Gram-negative bacteria }\end{array}$ \\
\hline $\begin{array}{l}\text { Target patient } \\
\text { population }\end{array}$ & Adults & $\begin{array}{l}\text { Literature data support a wide use of fluoroquinolone antibiotics in adults. It is a pregnancy } \\
\text { category } C \text { antibiotic, considered to be safe during breastfeeding. It is also allowed for pediatric } \\
\text { therapy but is never a first-line choice } \\
\text { Target patient group, as QTPP affects the dose selection and the route of administration }\end{array}$ \\
\hline $\begin{array}{l}\text { Route of } \\
\text { administration }\end{array}$ & Pulmonary administration & $\begin{array}{l}\text { A relatively new route of administration for local antibacterial therapy. Pulmonary application } \\
\text { avoids the first-pass effect and reduces systemic exposure and the risk of side effects }\end{array}$ \\
\hline Site of activity & Local effect & $\begin{array}{l}\text { Producing a local effect in pulmonary infections allows dose reduction of the antibiotics, } \\
\text { associated with a lower risk of side effects } \\
\text { Preselection of the desired site of activity as QTPP affects the API used, as well as the dose and } \\
\text { the dosage form selected }\end{array}$ \\
\hline Dosage form & $\begin{array}{l}\text { Dry powder for } \\
\text { pulmonary use }\end{array}$ & $\begin{array}{l}\text { Dry powders with a particle size of } 2-4 \mu \mathrm{m} \text { are required for the optimal deposition in lungs } \\
\text { Predetermination of the adequate dosage form is a QTPP according to the ICH Q8 guideline }\end{array}$ \\
\hline Dissolution profile & Increased dissolution & $\begin{array}{l}\text { Dissolution profile is a recommended QTPP as it affects the bioavailability and pharmacokinetics } \\
\text { and is critically related to the quality, safety, and efficacy of the medicinal product }\end{array}$ \\
\hline \multicolumn{3}{|r|}{ ( } \\
\hline $\begin{array}{l}\text { Excipients (quality } \\
\text { profile) }\end{array}$ & $\begin{array}{l}\text { Excipients assure proper } \\
\text { quality characteristics } \\
\text { by modifying the } \\
\text { size, morphology, } \\
\text { hydrophilicity, and stability } \\
\text { of the DPI product }\end{array}$ & $\begin{array}{l}\text { Polyvinyl alcohol } 3-88 \text { is a microfine coating material } \\
\text { The amino acid L-leucine can be well co-spray-dried with certain active compounds to modify } \\
\text { the drug's aerolization behavior } \\
\text { Dimethyl-beta cyclodextrin can be applied as a drug distribution enhancer } \\
\text { As CQAs, excipients are critically related to the dissolution and quality profile of the final } \\
\text { product }\end{array}$ \\
\hline $\begin{array}{l}\text { Particle size/specific } \\
\text { surface area (SSA) }\end{array}$ & $\begin{array}{l}\text { Homogeneous, } \\
\text { microsized product } \\
\text { of } 2-4 \mu \mathrm{m}\end{array}$ & $\begin{array}{l}\text { Microsize dimension has the optimal specific surface area and optimal administration properties } \\
\text { for pulmonary use } \\
\text { Size is critically related to pulmonary administration and to its local and/or systemic therapeutic } \\
\text { effect, thereby to product safety, efficacy, and quality }\end{array}$ \\
\hline Appearance & Microparticle & $\begin{array}{l}\text { Microparticle formulation is suitable to achieve an increased SSA, an improved wettability, and a } \\
\text { high amount of dissolved drug } \\
\text { It is critically related to efficacy }\end{array}$ \\
\hline Dissolution & $\begin{array}{l}\text { Improved dissolution rate } \\
(100 \% \text { in } 5 \mathrm{~min})\end{array}$ & $\begin{array}{l}\text { The dissolution profile highly affects the therapeutic effect. Accelerated drug release induces an } \\
\text { immediate local effect. It is related to the modification of the SSA, wettability, and solubility }\end{array}$ \\
\hline Wettability & Hydrophyl product & $\begin{array}{l}\text { Wettability is critical for the drug's adhesion the pulmonary mucosa. It is critically related to } \\
\text { efficacy }\end{array}$ \\
\hline $\begin{array}{l}\text { Structure (crystalline/ } \\
\text { amorphous) }\end{array}$ & $\begin{array}{l}\text { Stable form } \\
\text { (crystalline/amorphous) }\end{array}$ & $\begin{array}{l}\text { The crystalline or the amorphous state of the API affects stability and release properties. It is } \\
\text { critically related to efficacy and quality }\end{array}$ \\
\hline Solubility & Water-soluble & Solubility has a remarkable influence on the bioavailability of the drug/product \\
\hline \multicolumn{3}{|l|}{ CPPs } \\
\hline $\begin{array}{l}\text { Composition } \\
\text { (co-spray drying) }\end{array}$ & $\begin{array}{l}\text { Micronized size, stabilized } \\
\text { structure using additives }\end{array}$ & $\begin{array}{l}\text { Additives contribute to reaching the desired and predefined quality of the final co-spray-dried } \\
\text { product }\end{array}$ \\
\hline $\begin{array}{l}\text { Inlet temperature } \\
\text { (co-spray drying) }\end{array}$ & $130^{\circ} \mathrm{C}$ & $\begin{array}{l}\text { Inlet temperature has a critical influence on optimal drying and thus influences the final } \\
\text { product's appearance }\end{array}$ \\
\hline $\begin{array}{l}\text { Outlet temperature } \\
\text { (co-spray drying) }\end{array}$ & $75^{\circ} \mathrm{C}$ & $\begin{array}{l}\text { Outlet temperature has a critical influence on optimal drying of the desired co-spray-dried } \\
\text { final product }\end{array}$ \\
\hline $\begin{array}{l}\text { Feed rate } \\
\text { (co-spray drying) }\end{array}$ & $5 \mathrm{~mL} \cdot \mathrm{min}^{-1}$ & Feed rate has a critical influence on the formation of co-micronized particles \\
\hline
\end{tabular}

Abbreviations: QTPPs, quality target product profiles; CQAs, critical quality attributes; CPPs, critical process parameters; DPI, dry powder inhalation.

spherical geometry in contrast to the DPI of CIP containing LEU which was found to be cavitated. Such deep cavities can also be observed in the DPI containing cyclodextrin, but those cavities are less deep than those in the DPI of CIP containing LEU. The DPI of CIP containing PVA, LEU, and $\mathrm{CD}$ contains no cavities, which may result from the dominant effect of PVA to produce smooth surfaces.

\section{Structural characteristics}

\section{Differential scanning calorimetry}

A sample containing only raw CIP was prepared by the same method to serve as a control. The thermal response of CIP alone had a broad diffuse endothermic peak at about $145^{\circ} \mathrm{C}$ indicative of recrystallization and a sharp endothermic peak at $312^{\circ} \mathrm{C}$ indicative of melting. 


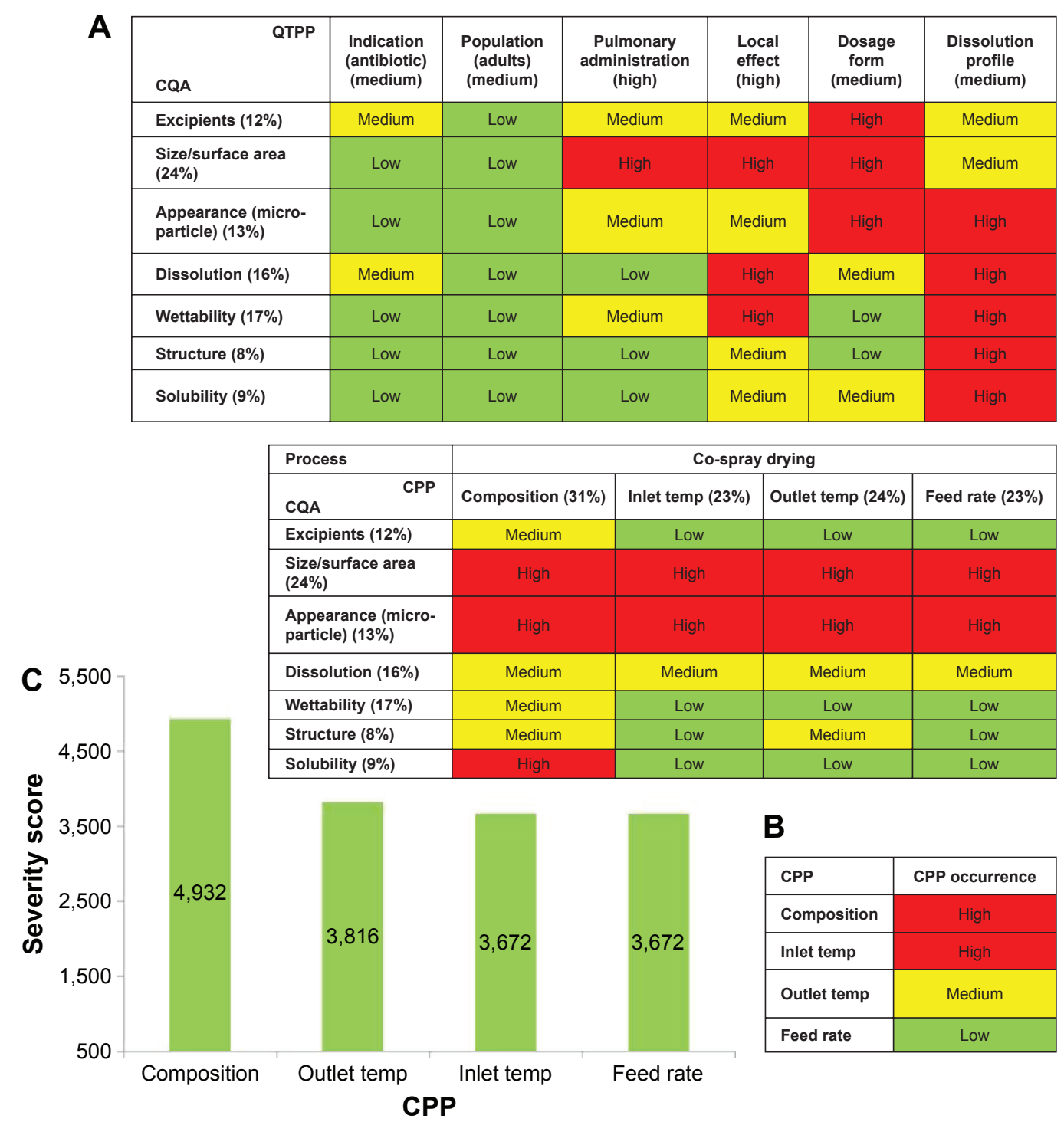

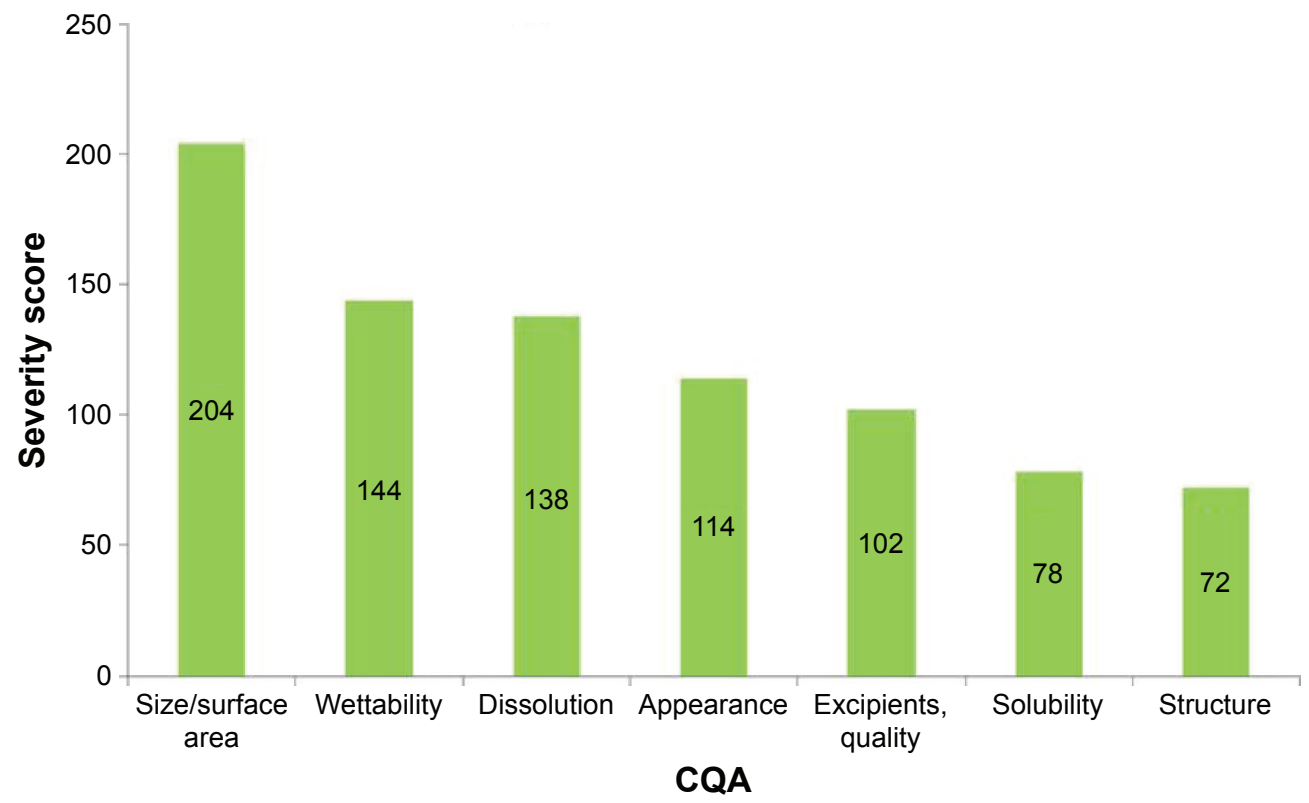

Figure 2 Results of (A) the interdependence rating of the QTPPs and CQAs and of the CPPs and CQAs, (B) the occurrence rating of the CPPs, and (C) Pareto charts of the CQAs and CPPs with calculated numeric severity scores generated by the RA software.

Abbreviations: QTPPs, quality target product profiles; CQAs, critical quality attributes; CPPs, critical process parameters; RA, risk assessment. 
Table 4 Particle size of the microparticles of various compositions prepared

\begin{tabular}{lllll}
\hline Material & $\begin{array}{l}\mathbf{D}(\mathbf{0 . 1}) \\
\mu \mathbf{m}\end{array}$ & $\begin{array}{l}\mathbf{D}(\mathbf{0 . 5}) \\
\mu \mathbf{m}\end{array}$ & $\begin{array}{l}\mathbf{D}(\mathbf{0 . 9}) \\
\mu \mathbf{m}\end{array}$ & $\begin{array}{l}\text { Specific surface } \\
\text { area }\left(\mathbf{m}^{2} \cdot \mathbf{g}^{-1}\right)\end{array}$ \\
\hline CIP_SPD & $1.3 \mathrm{I} \pm 0.01$ & $2.44 \pm 0.02$ & $4.44 \pm 0.01$ & $2.76 \pm 0.03$ \\
CIP_PVA_SPD & $1.22 \pm 0.04$ & $2.38 \pm 0.03$ & $4.57 \pm 0.03$ & $2.85 \pm 0.02$ \\
CIP_CD_SPD & $1.68 \pm 0.03$ & $3.02 \pm 0.06$ & $5.24 \pm 0.04$ & $2.20 \pm 0.09$ \\
CIP_LEU_SPD & $1.62 \pm 0.05$ & $2.84 \pm 0.02$ & $4.84 \pm 0.00$ & $2.33 \pm 0.01$ \\
CIP_PVA_ & $1.58 \pm 0.06$ & $3.27 \pm 0.01$ & $6.42 \pm 0.02$ & $2.14 \pm 0.02$ \\
CD_LEU_SPD & & & &
\end{tabular}

Abbreviations: PVA, polyvinyl alcohol; CIP, ciprofloxacin hydrochloride; LEU, L-leucine; CD, cyclodextrin; SPD, spray drying.

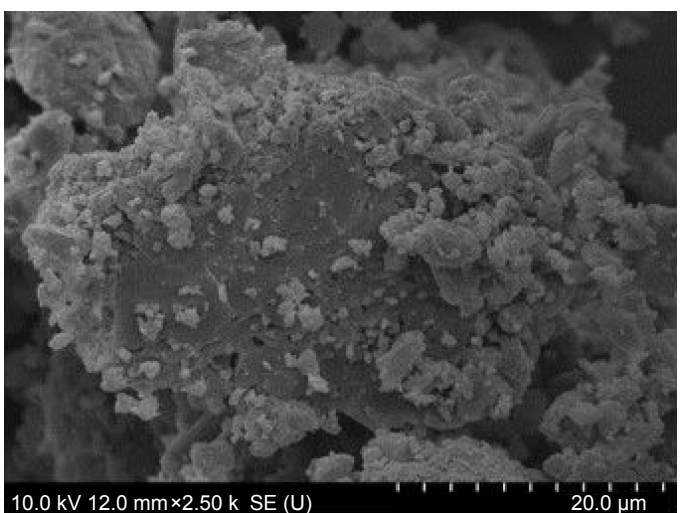

CIP_RAW

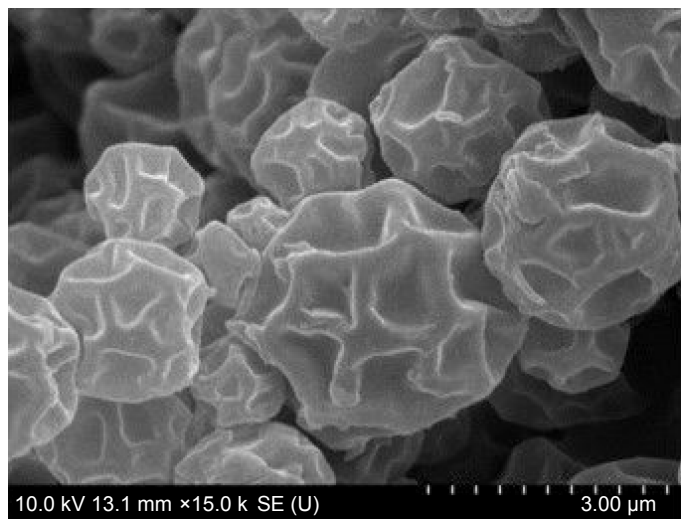

CIP_LEU_SPD

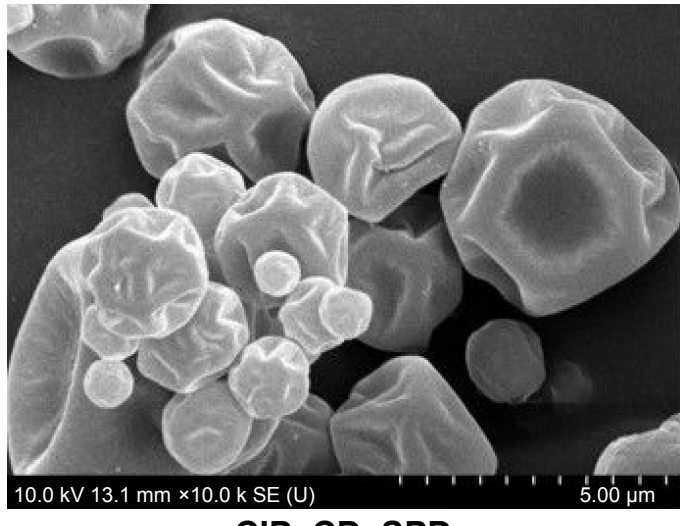

CIP_CD_SPD
In the thermograms of microparticles containing CIP and PVA, characteristic endothermic peaks were detected. There were two exothermic peaks at $152^{\circ} \mathrm{C}$ and $190^{\circ} \mathrm{C}$ due to recrystallization during spray drying, and a sharp endothermic peak was detected at $312^{\circ} \mathrm{C}$ indicative of melting. Interestingly, the microparticles containing $\mathrm{CD}$ were shown to have a lower melting point at $207^{\circ} \mathrm{C}$ due to their amorphous structure resulting from spray drying. The microparticles containing LEU were shown to have two different endothermic peaks at $270^{\circ} \mathrm{C}$ and $308^{\circ} \mathrm{C}$ indicating the melting
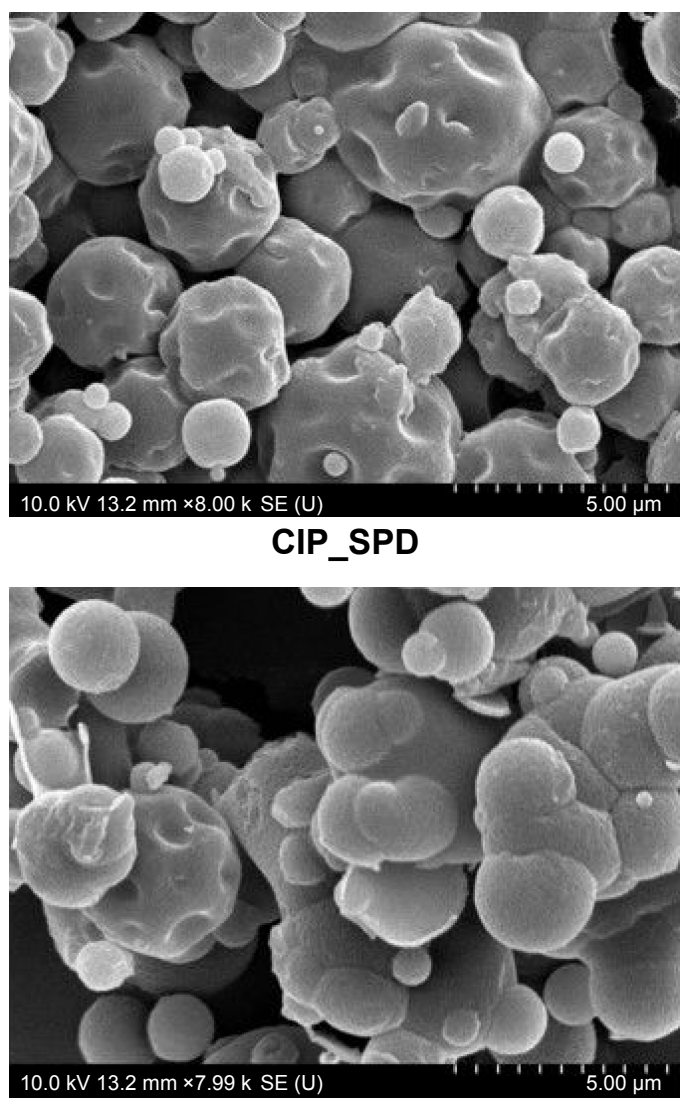

CIP_PVA_CD_LEU_SPD

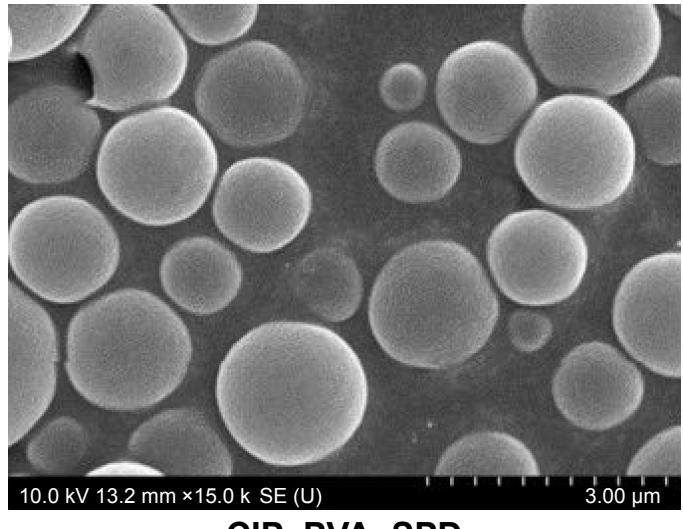

CIP_PVA_SPD

Figure 3 Scanning electron micrographs of the spray-dried microparticles.

Abbreviations: CIP, ciprofloxacin hydrochloride; SPD, spray drying; RAW, unattended material; CD, cyclodextrin; LEU, L-leucine; PVA, polyvinyl alcohol. 
points of LEU and CIP, respectively. Figure 4 shows the DSC thermograms of raw CIP and of the different CIP-containing microparticles investigated.

\section{X-ray powder diffraction}

The XRPD diffractogram of raw CIP shows many characteristic peaks indicating a high degree of crystallinity, but the peak with the highest intensity is at $9.09^{\circ} 2 \theta$ area.

Since the spray-drying parameters were similar for all the formulations, the differences in crystallinity must be attributable to the presence of the different excipients. The spray-dried products containing excipients exhibit a large degree of amorphicity and a very low degree of crystallinity. The only product that shows significant crystallinity is the DPI of CIP containing LEU, suggesting that the co-spray-dried formulation is composed of crystalline LEU and amorphous CIP. Formulations containing CD have a completely amorphous character. The characteristic peaks of spray-dried microparticles at 62 -Theta degree show the tendency of CIP to recrystallize from its polymorph. The XRPD diffractograms of raw CIP and of the microparticle compositions investigated are seen in Figure 5.

\section{Fourier-transform infrared spectroscopy}

The FT-IR spectrum revealed that raw CIP exhibits a peak at $1,707 \mathrm{~cm}^{-1}$ as a consequence of the cyclic $\mathrm{C}=\mathrm{O}$ stretching that induces a shift toward the higher wave numbers due to the association with the $\mathrm{OH}$ groups of other components. The magnitude of the shift in the $\mathrm{C}=\mathrm{O}$ stretching for the bounded dimer form is inversely proportional to the strength of the interaction between CIP and the excipients.
The other feature detectable at the FT-IR spectrum is the widening of the $\mathrm{C}=\mathrm{O}$ stretching bond, caused by the configuration of the hydrogen realignment between the excipients and the $\mathrm{C}=\mathrm{O}$ bond of ciprofloxacin. The shift of the above bond indicates that the interaction between CIP and LEU or PVA is weaker than that between CIP and CD. The bands assigned to N-H in the FT-IR spectrum are seen at $1,612 \mathrm{~cm}^{-1}$. For the microparticles containing excipients, several peaks are missing. The peaks at $987 \mathrm{~cm}^{-1}$ have completely disappeared in all cases due to the change from the dimeric to the monomeric state. The bands assigned to N-H in the FT-IR spectrum can be seen at $1,612 \mathrm{~cm}^{-1}$ both in the raw CIP and in the spray-dried microparticle compositions. Figure 6 shows the FT-IR spectra of the raw material and the microparticle compositions investigated.

\section{In vitro characteristics}

\section{Aerodynamic particle size analysis}

Generally, the single spray-dried CIP formulation had a low aerosol performance ( $\mathrm{FPF}=31.68 \pm 1.43$ ). In contrast, the combined spray-dried formulations containing CIP plus excipients exhibited a significantly improved aerosol performance. While even the presence of PVA or CD raised the FPF value of the microparticles, those containing LEU were characterized by the highest aerosol performance. These results show that the use of excipients can significantly improve the aerodynamic behavior of CIP-containing microparticles. LEU has the highest potential to improve the aerosol performance $(\mathrm{FPF}=80.27 \% \pm 1.65 \%)$. This value indicates that more than $80 \%$ of the particles delivered from the inhaler have a volume aerodynamic diameter less than $5 \mu \mathrm{m}$.

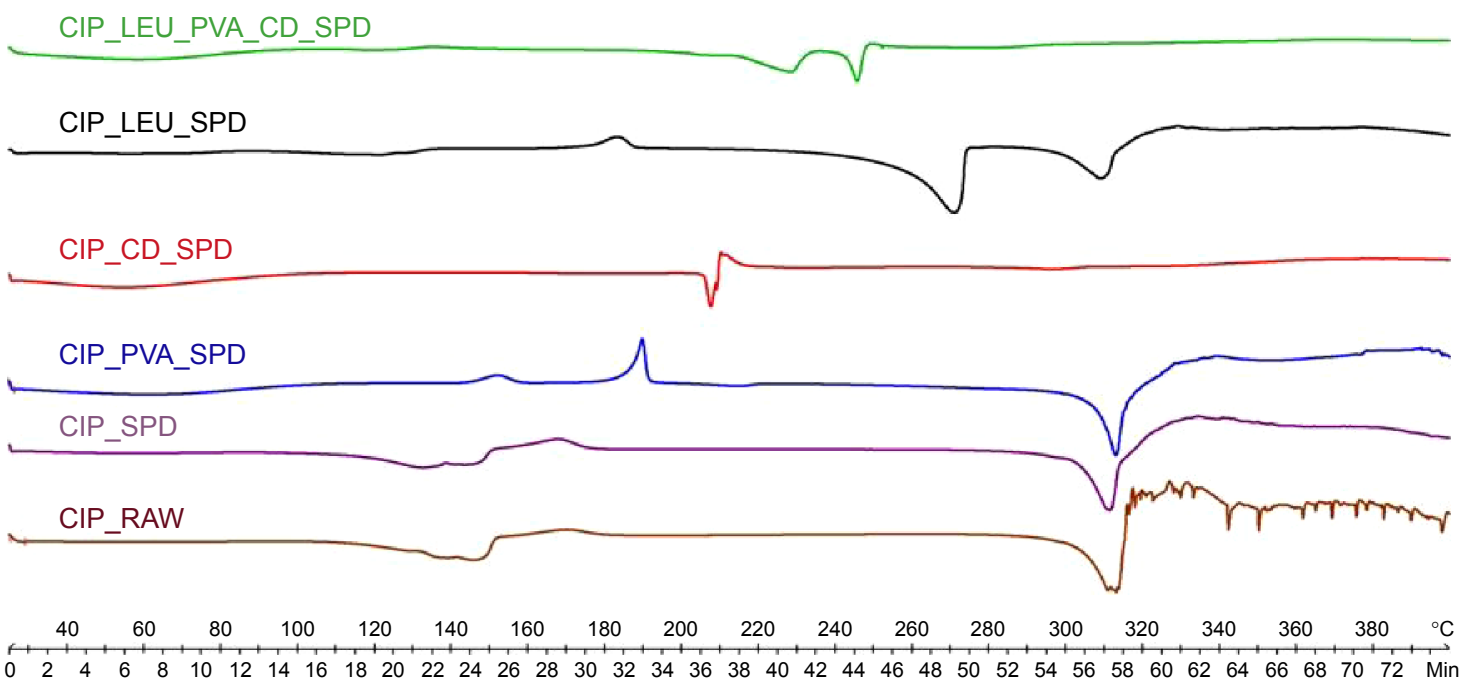

Figure 4 Thermograms of raw CIP and of the different CIP-containing microparticles investigated.

Abbreviations: CIP, ciprofloxacin hydrochloride; SPD, spray drying; RAW, unattended material; CD, cyclodextrin; LEU, L-leucine; PVA, polyvinyl alcohol. 


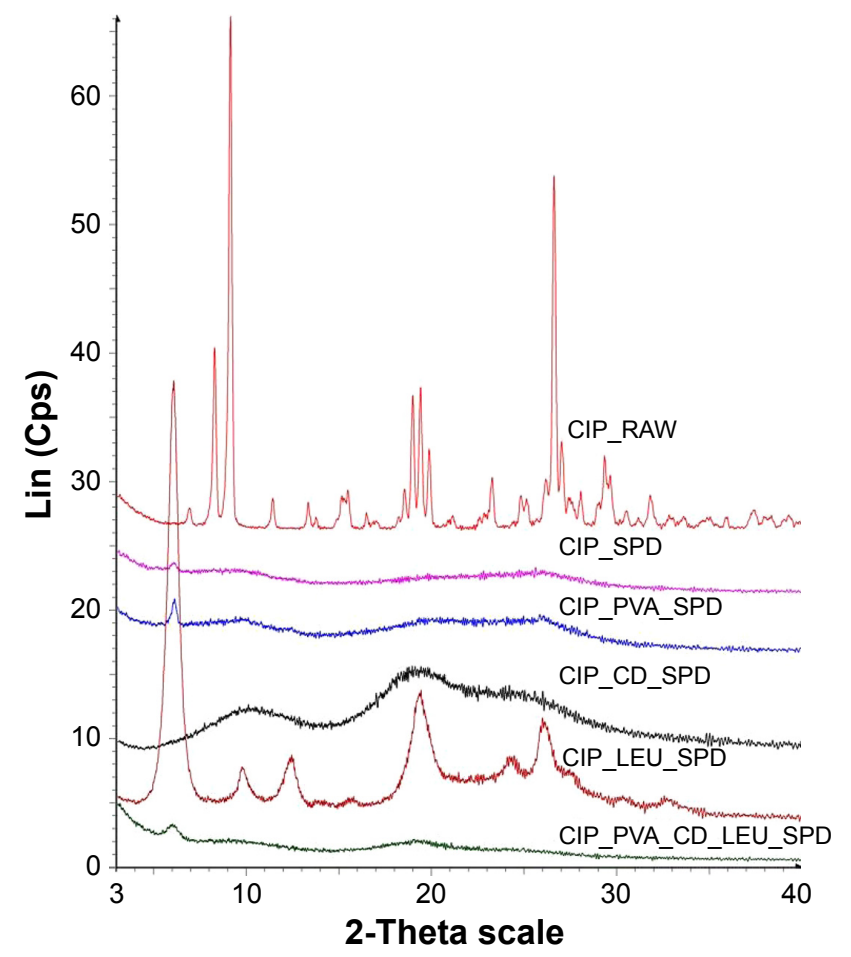

Figure 5 XRPD diffractograms of raw CIP and of the CIP-containing microparticle compositions investigated.

Abbreviations: XRPD, X-ray powder diffraction; CIP, ciprofloxacin hydrochloride; SPD, spray drying; RAW, unattended material; CD, cyclodextrin; LEU, L-leucine; PVA, polyvinyl alcohol.
Drug contents, FPF, median aerodynamic diameter, and ED values are shown in Table 5 .

\section{Dissolution test}

Solubility test as a preliminary experiment was carried out. Table 6 shows the solubility of CIP. In accordance with literature data, our measurements confirmed that the increase in $\mathrm{pH}$ decreases the solubility of CIP. ${ }^{28}$

Dissolution tests focused on free CIP release. Figure 7 shows ciprofloxacin release from the microparticles at $\mathrm{pH}$ 7.4. A slower rate of CIP release was observed for the spray-dried microparticles containing PVA compared to those without PVA. This behavior can be interpreted by the controlled release induced by PVA. Drug release was shown to rise substantially in the presence of LEU and CD, and microparticles containing LEU as the only excipient were shown to be characterized by the highest rate of CIP release, with full API release within 3 min.

\section{Conclusion}

Pulmonary infections are highly common and often recurrent. A possible therapeutic approach is to deliver antibiotics directly to the site of the infection in order to

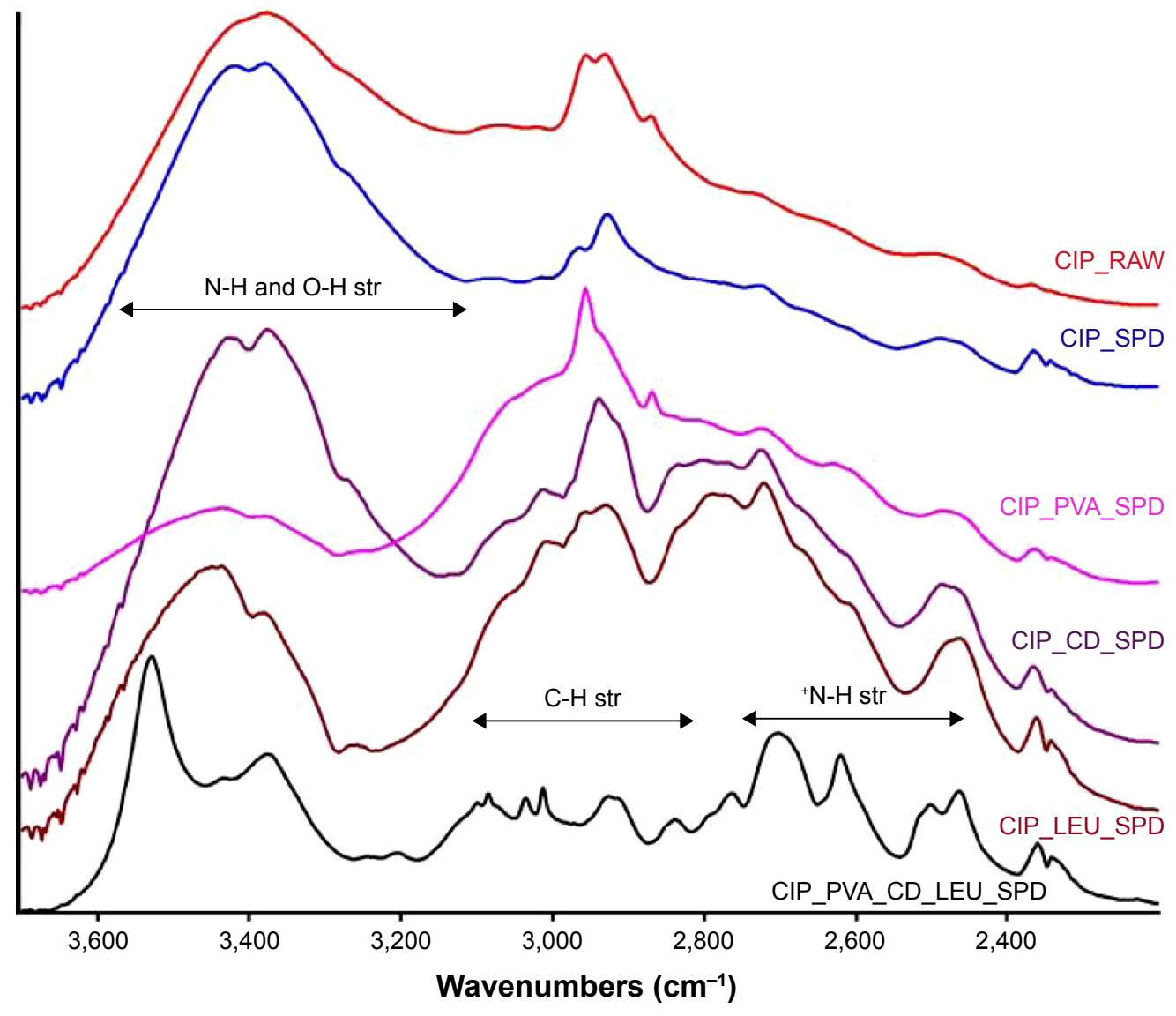

Figure 6 (Continued) 


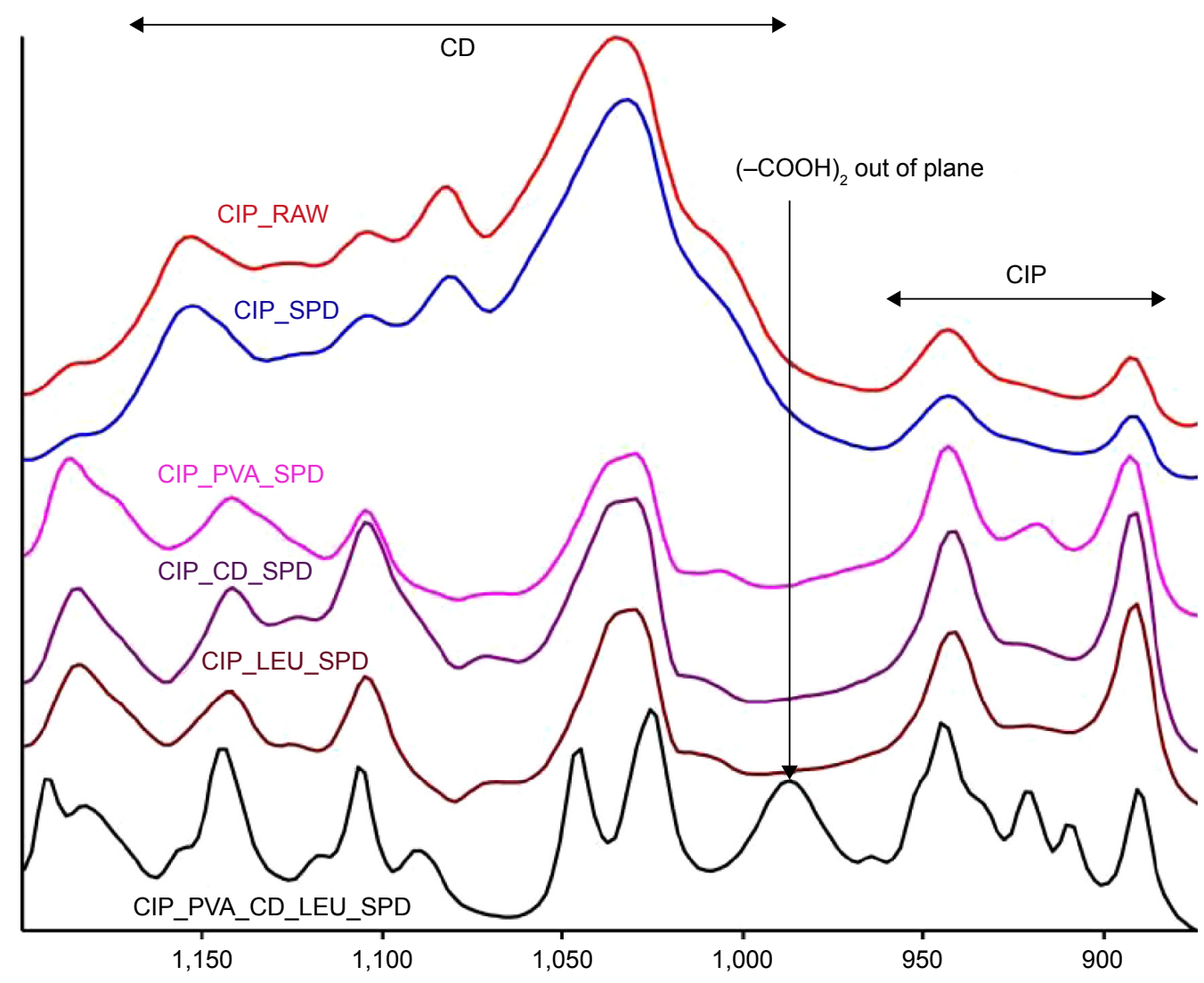

Figure 6 FT-IR spectra of ciprofloxacin hydrochloride (CIP) and the CIP-containing microparticle compositions investigated.

Abbreviations: FT-IR, Fourier-transform infrared spectroscopy; SPD, spray drying; RAW, unattended material; CD, cyclodextrin; LEU, L-leucine; PVA, polyvinyl alcohol.

increase local (effective) drug concentration and decrease the chance of adverse effects. In this study microparticles of CIP hydrochloride for DPI were prepared by spray-drying technology, applying predefined optimal drug formulation parameters.

The QbD-based formulation design helped to synthesize the relevant knowledge both from the literature and from previous experience, using modern quality-management tools. The QbD methodology and the RA tools were able

Table 5 Drug content, fine particle fraction (FPF), mass median aerodynamic diameter (MMAD), and emitted dose (ED) of the CIP-containing microparticle compositions investigated

\begin{tabular}{lllll}
\hline DPI & $\begin{array}{l}\text { Drug } \\
\text { content (\%) }\end{array}$ & FPF (\%) & $\begin{array}{l}\text { MMAD } \\
(\mu \mathrm{m})\end{array}$ & ED (\%) \\
\hline CIP_SPD & $100 \pm 0$ & $31.68 \pm 1.4$ & $7.23 \pm 0.01$ & $99.95 \pm 0.5$ \\
CIP_PVA_SPD & $85 \pm 0.07$ & $60.18 \pm 1.3$ & $3.61 \pm 0.05$ & $95.92 \pm 0.4$ \\
CIP_CD_SPD & $59 \pm 0.03$ & $58.54 \pm 1.1$ & $3.19 \pm 0.01$ & $96.93 \pm 0.5$ \\
CIP_LEU_SPD & $72 \pm 0.08$ & $80.27 \pm 1.7$ & $2.15 \pm 0.08$ & $95.81 \pm 0.6$ \\
CIP_PVA_ & $45 \pm 0.24$ & $45.93 \pm 1.4$ & $4.53 \pm 0.02$ & $97.68 \pm 0.4$ \\
CD_LEU_SPD & & & & \\
\hline
\end{tabular}

Abbreviations: PVA, polyvinyl alcohol; CIP, ciprofloxacin hydrochloride; LEU, L-leucine; CD, cyclodextrin; SPD, spray drying. to select the critical factors (CQAs and CPPs) that have the highest influence on the dedicated DPI production procedure, and thus on the quality of the final DPI product. The critical factors were not only identified but also ranked and prioritized according to their calculated precise severity (impact) scores. It has been established that the particle size of the API, the wettability and dissolution characteristics, as well as the composition of the DPI product are to be focused on during the practical development phase. The different DPI formulations were prepared according to these preliminary parameter rankings and priority classifying. After the subsequent development in practice it should be determined whether all the particles produced are in acceptable particle size for optimal deposition in the lungs.

Table 6 Maximum measured concentration of ciprofloxacin hydrochloride filtered saturated solution

\begin{tabular}{llll}
\hline Solvent & $\mathbf{p H}$ & $\begin{array}{l}\text { Concentration } \\
\left(\mathbf{m g} \cdot \mathbf{m L}^{-1}\right)\end{array}$ & $\begin{array}{l}\lambda \text { max } \\
(\mathbf{n m})\end{array}$ \\
\hline Buffer solution & 7.4 & 6.3 & $27 I$ \\
Distilled water & 4.4 & 41.9 & 275 \\
\hline
\end{tabular}




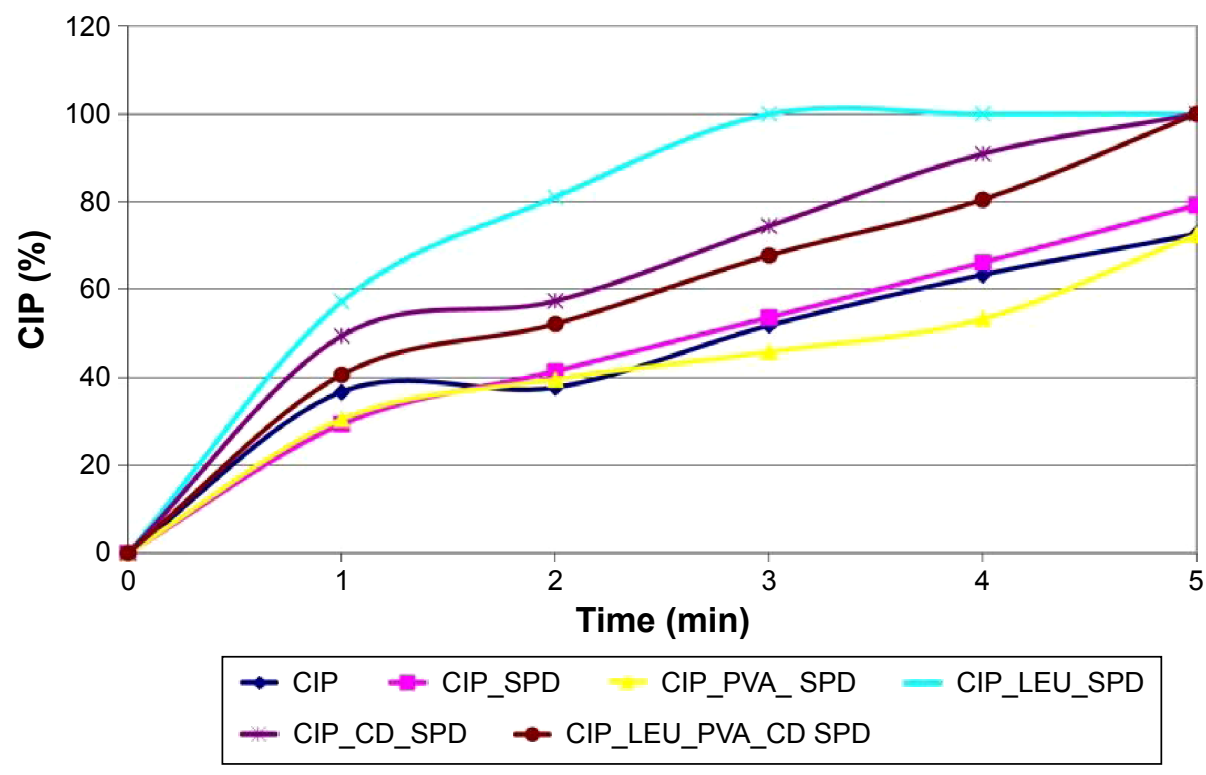

Figure 7 Kinetic plots of free ciprofloxacin release from the microparticles investigated.

Abbreviations: CIP, ciprofloxacin hydrochloride; SPD, spray drying; CD, cyclodextrin; LEU, L-leucine; PVA, polyvinyl alcohol.

Using PVA as an excipient for the CIP-containing DPI was shown to decrease the size of the microparticles significantly. The application of LEU to the microparticles induced a significant improvement in the FPF and in the aerodynamic behavior, and also allows a very fast drug release. Besides the adequate formula development, this study confirmed that the QbD-guided modern research methodology could be properly used in the early development phase of innovative formulations like DPIs and resulted in a risk-based and effective product development. In addition, applying $\mathrm{QbD}$ in such studies could help to avoid profitless efforts in further phases of the development process.

\section{Acknowledgment}

This project was supported by the Janos Bolyai Research Scholarship of the Hungarian Academy of Sciences (2014-2017).

\section{Disclosure}

The authors report no conflicts of interest in this work.

\section{References}

1. Anderson PJ. History of aerosol therapy liquid nebulization to MDIs to DPIs. Respir Care. 2005;50(9):1139-1150.

2. Pilcer G, Rosière R, Traina K, Sebti T, Vanderbist F, Amighi K. New co-spray-dried tobramycin nanoparticles-clarithromycin inhaled powder systems for lung infection therapy in cystic fibrosis patients. $J$ Pharm Sci. 2013;102(6):1836-1846.

3. Gelperina S, Kisich K, Iseman MD, Heifets L. The potential advantages of nanoparticle drug delivery systems in chemotherapy of tuberculosis. Am J Respir Crit Care Med. 2005;172(12):1487-1490.

4. Wu L, Miao X, Shan Z, et al. Studies on the spray dried lactose as carrier for dry powder inhalation. Asian J Pharm Sci. 2014;9(6):336-341.
5. Sung JC, Pulliam BL, Edwards DA. Nanoparticles for drug delivery to the lungs. Trends Biotechnol. 2007;25(12):563-570.

6. Yang Y, Bajaj N, Xu P, Ohn K, Tsifansky MD, Yeo Y. Development of highly porous large PLGA microparticles for pulmonary drug delivery. Biomaterials. 2009;30(10):1947-1953.

7. Cipolla D, Chan H-K. Inhaled antibiotics to treat lung infection. Pharm Pat Anal. 2013;2(5):647-663.

8. Fawaz F, Guyot M, Lagueny AM, Devissaguet JP. Ciproflexacin-loaded polyisobutylcyanoacrylate nanoparticles: preparation and characterization. Int J Pharm. 1997;154:191-203.

9. Masadeh MM, Alzoubi KH, Khabour OF, Al-Azzam SI. Ciprofloxacininduced antibacterial activity is attenuated by phosphodiesterase inhibitors. Curr Ther Res Clin Exp. 2015;77:14-17.

10. Zhao H, Le Y, Liu H, et al. Preparation of microsized spherical aggregates of ultrafine ciprofloxacin particles for dry powder inhalation (DPI). Powder Technol. 2009;194:81-86.

11. Weers JG, Miller DP. Formulation design of dry powders for inhalation. J Pharm Sci. 2015;104(10):3259-3288.

12. Islam N, Gladki E. Dry powder inhalers (DPIs) - A review of device reliability and innovation. Int J Pharm. 2008;360(1-2):1-11.

13. Stass H, Weimann B, Nagelschmitz J, Rolinck-Werninghaus C, Staab D. Tolerability and pharmacokinetic properties of ciprofloxacin dry powder for inhalation in patients with cystic fibrosis: a phase I, randomized, dose-escalation study. Clin Ther. 2013;35(10):1571-1581.

14. Zhou Q, Shui Yee Leung S, Tang P, Parumasivam T, Hui Loh Z, Chan H-K. Inhaled formulations and pulmonary drug delivery systems for respiratory infections. Adv Drug Deliv Rev. 2015;85:83-99.

15. Yu LX, Amidon G, Khan MA, et al. Understanding pharmaceutical quality by design. AAPS J. 2014;16(4):771-783.

16. ICH. ICH Harmonised Tripartite Guideline. Pharmaceutical Development Q8(R2); 2009. Available from: http://www.ich.org/fileadmin/ Public_Web_Site/ICH_Products/Guidelines/Quality/Q8_R1/Step4/ Q8_R2_Guideline.pdf. Accessed September 30, 2016.

17. ICH. ICH Harmonised Tripartite Guideline. Quality Risk Manegement Q9; 2005. Available from: http://www.ich.org/fileadmin/ Public_Web_Site/ICH_Products/Guidelines/Quality/Q9/Step4/Q9_ Guideline.pdf. Accessed September 30, 2016.

18. ICH. ICH Harmonised Tripartite Guideline. Pharmaceutical Quality System Q10; 2008. Available from: http://www.ich.org/fileadmin/ Public_Web_Site/ICH_Products/Guidelines/Quality/Q10/Step4/ Q10_Guideline.pdf. Accessed September 30, 2016. 
19. Amasya G, Badilli U, Aksu B, Tarimci N. Quality by design case study 1 : design of 5-fluorouracil loaded lipid nanoparticles by the W/O/W double emulsion - solvent evaporation method. Eur J Pharm Sci. 2016;84: 92-102.

20. Wu X, Hayes D, Zwischenberger JB, Kuhn RJ, Mansour HM. Design and physicochemical characterization of advanced spray-dried tacrolimus multifunctional particles for inhalation. Drug Des Devel Ther. 2013;7:59-72.

21. Healy AM, Amaro MI, Paluch KJ, Tajber L. Dry powders for oral inhalation free of lactose carrier particles. Adv Drug Deliv Rev. 2014; 75:32-52.

22. Fujii H. Decomposition analysis of green chemical technology inventions from 1971 to 2010 in Japan. J Clean Prod. 2016;112:4835-4843.

23. Wu X, Zhang W, Hayes D, Mansour HM. Physicochemical characterization and aerosol dispersion performance of organic solution advanced spray-dried cyclosporine A multifunctional particles for dry powder inhalation aerosol delivery. Int J Nanomedicine. 2013;8:1269-1283.
24. Belotti S, Rossi A, Colombo P, et al. Spray dried amikacin powder for inhalation in cystic fibrosis patients: a quality by design approach for product construction. Int J Pharm. 2014;471(1-2):507-515.

25. Heijerman H, Westerman E, Conway S, et al. Inhaled medication and inhalation devices for lung disease in patients with cystic fibrosis: a European consensus. J Cyst Fibros. 2009;8(5):295-315.

26. Ambrus R, Szabó B, Szabó-Révész P. Development of dry powder carrier systems for pulmonary application. First European Conference on Drug Delivery; April 13-14, 2015; Reims, France; p. 111.

27. Labiris NR, Dolovich MB. Pulmonary drug delivery. Part II: The role of inhalant delivery devices and drug formulations in therapeutic effectiveness of aerosolized medications. Br J Clin Pharmacol. 2003; 56(6):600-612.

28. Olivera ME, Manzo RH, Junginger HE, et al. Biowaiver monographs for immediate release solid oral dosage forms: ciprofloxacin hydrochloride. J Pharm Sci. 2011;100(1):22-33.

\section{Publish your work in this journal}

Drug Design, Development and Therapy is an international, peerreviewed open-access journal that spans the spectrum of drug design and development through to clinical applications. Clinical outcomes, patient safety, and programs for the development and effective, safe, and sustained use of medicines are the features of the journal, which has also been accepted for indexing on PubMed Central. The manuscript management system is completely online and includes a very quick and fair peer-review system, which is all easy to use. Visit http://www.dovepress.com/testimonials.php to read real quotes from published authors.

Submit your manuscript here: http://www.dovepress.com/drug-design-development-and-therapy-journal 